\title{
The impact of confinement on school-aged children
}

DOI: $10.46932 / \mathrm{sfjdv2n1-003}$

Received in: January 1st, 2020

Accepted in: March 30th, 2020

\author{
Ángela García Nicolás \\ Graduada Educación Primaria. Especialista en Audición y Lenguaje. \\ Institution: RG Formación \\ Calle Rosalía de Castro, 44, 30107 Murcia \\ Lucía Martinez Martinez \\ Graduada Educación Primaria. Especialista en Audición y Lenguaje. \\ Institution: RG Formación \\ Calle Rosalía de Castro, 44, 30107 Murcia \\ Nuria Muñoz Lázaro \\ Graduada Educación Primaria. Especialista en Audición y Lenguaje. \\ Institution: RG Formación \\ Calle Rosalía de Castro, 44, 30107 Murcia \\ Valeria Simaro Faura \\ Graduada Educación Primaria. Especialista en Audición y Lenguaje. \\ Institution: RG Formación \\ Calle Rosalía de Castro, 44, 30107 Murcia \\ Jose María Rabal Alonso \\ Profesor ISEN Centro Universitario \\ Institution: ISEN \\ Calle Menéndez y Pelayo, 8, 30204 Cartagena, Murcia \\ E-mail: josemaria.rabal@um.es
}

\begin{abstract}
Confinement is affecting the health of the entire society, although, to a greater extent with the little ones, causing them stress, fear, anxiety, worry, depression and irritability along with all the consequences that this entails. This has been caused by the health status of family members, friends or your own; conditions of confinement; school closings; loss of contact with peer groups; limitations for movement and recreational activities; teaching activities and restrictions on psychological interventions. This has affected children with physical, emotional and psychological effects. For this reason, it is pointed out that families should be aware of children to detect the symptoms of these disorders and prevent them from going to more.
\end{abstract}

Keywords: confinement, health status, limitations, children, physical, psychological, emotional effects.

\section{THEORETICAL FRAMEWORK.}

According to the psychologist Álvarez (2020), confinement is affecting the health of the little ones, causing them a dangerous stress that we should help them fight for the good of their health.

Confinement affects the key areas of the neutral development of early childhood (up to 7 years): movement, social relationships, play or learning (Sáez, 2020).

All this is due to the fact that they cannot be in close contact with their peers or with their teachers since they must maintain a safe distance and these people are very important reference figures for them at 
these ages. In addition, they cannot go out to play in the park as they normally did. If we add to this that they do not understand the situation as adults do, this generates fear, anxiety and stress that they do not know how to manage because they still do not have the psychological tools to do so, according to the health psychologist of the Children's Mental Health Center. and Juvenil de Gracia, Lluís Díaz (2020).

However, the clinical psychologist of the Early Care Unit and Autism Unit of the Sant Joan Maria Elias hospital (2020) points out that although there is no scientific evidence of how this new situation can affect children, it is known that it can increase the risk of stress and anxiety.

For his part, Álvarez (2020) points out that in previous studies carried out on the impact of isolation in pandemics, it is shown that there is a four times higher probability of post-traumatic stress in children who have experienced this pandemic situation, than those who fortunately they have not been through this. This psychologist explains that post-traumatic stress is a serious psychiatric disorder that can only be diagnosed four months after the situation that caused this disorder.

Therefore, Álvarez (2020) points out that families should be aware of children to detect the symptoms of this disorder and prevent them from getting worse, since both children and adults could become ill if these symptoms are not treated early .

The symptoms of this phenomenon can be: nervous tics, less sleep, fear or irritability.

Due to all the aforementioned, experts advise listening to children, talking about the fears and feelings they experience, as well as showing them a lot of affection and affection through physical contact.

According to the pediatrician of the Child Development and Early Care Center of Gracia, Núria Bea (2020), not all children experience confinement in the same way, this depends on how the child himself is and his ability to resist traumatic situations, but It also depends a lot on how the family manages the distress situation at home, providing security for their children.

There is no doubt that children are capable of overcoming this situation, but for this, accompaniment is important to help them manage what is happening.

Finally, another important aspect highlighted by the psychologist and family therapist Gus Bas (2020) is that the way to cope with this situation also depends a lot on the resources that the family can offer their children because families with a good economic situation they do have the ability to telecommute and spend time with their children. However, there are many parents who must go to their workplace while schools remain closed, although the impact this could have on children remains to be seen.

Due to the inequality that families have to cope with the situation, Bas (2020) points out that this crisis has been managed in a capitalist way.

Castillo, Castillo, Ferrer and González (2020), show a study carried out with the objective of detecting those minors who were at risk in terms of relational problems and depression. To carry out the study, a tool was administered to broad groups in our environment such as the school group.

First, an anonymous form was made, which was addressed to students between the ages of 8 and 18 
and their caregivers. This questionnaire was divided into two parts: the first was addressed to the adult caregiver who had to fill in including demographic data and giving the explicit consent that allowed the minor to fill out the second part. This second part had to be completed by the child and included questions referring to aspects such as the evaluation of the relationship between equals through items adapted to distance relationships with Information and Communication Technologies (ICT), and a last block which delved into personal and family dynamics during confinement.

Finally, a total of 409 responses were collected, obtaining $97.1 \%$ consent to the answer from the minors. $19.2 \%$ of the boys scored above the risk threshold of suffering from depression and in the case of girls, a higher proportion of participants was found above this threshold (23.6\% vs $13 \%)$. Something similar was also observed among the group of schoolchildren who during confinement had only one main caregiver (26.0\% vs $16.3 \%$ in children with two or more caregivers). On the other hand, $50.6 \%$ of participants answered that they were often or always worried about pain and illness.

Most of the participants showed little change in terms of the quality of the relationship between equals carried out through ICT. With regard to routines during confinement, it is found that $60.7 \%$ had practiced less physical exercise and a large part (85.9\%) had used devices with a screen for longer than before. $70.3 \%$ of the participants answered that their main concerns were that they or someone close to them would become ill and not being able to see their friends and family (61.5\%).

In conclusion, Castillo et al. (2020), affirms that according to the depression indicators collected in the questionnaire, no great differences have been obtained with respect to previous data in a similar population, despite the sad social and health situation. In the same way that the relationships of the participants with their peers do not show differences in their quality, that is, this aspect has not been reduced during confinement.

On the other hand, Ribot, Chang and González (2020) affirm that mental health can be understood as a multidisciplinary construct that is composed of personal, social and public policy conditions. Therefore, when unforeseen and disastrous situations such as epidemics or health emergencies appear, this leads to great changes in relationship dynamics, which has a significant effect on people's mental health.

Due to the appearance of COVID-19, health and government authorities were forced to implement measures in order to prevent the disease from spreading as little as possible, for this reason they decided to establish quarantine and isolation of the population. Although each person reacts differently to such measures, the feelings that are most frequently manifested are anxiety, worry or fear related to their own health, and that of family, friends and acquaintances, loss of income and security in the workplace, the need to provide sufficient amounts of food and medicine, concern for the care of family members, ignorance of the duration of the situation,

This situation is linked to constant exposure to alarming news that causes even more feelings of victimization, discomfort and personal vulnerability. Furthermore, it seems that in risky situations, the 
emotional-affective dimension of the information reception processes intensifies over the cognitive dimension. Villegas (2020) says that the first human reaction to such epidemics is panic, fear of suffering and death. Followed by panic is flight and a feeling of guilt when considering illness as punishment.

In these situations, the effects are more notable in populations that live in precarious conditions and have limited resources and have limited access to social and health services. Therefore, the evaluation of psychosocial risk is necessary, defined as the probability that a traumatic situation causes a very high value of social and mental damage, that is, it refers to the result between external and internal conditions. In this case, the epidemic corresponds to the external factor with respect to the population and vulnerability is the internal condition of the person exposed to an epidemic threat. In this sense, there are differences in vulnerability between the different population groups since in general, more vulnerable are those groups that have suffered the greatest losses and that find it more difficult to rebuild their lives and find social support after the epidemic. On the other hand, men's emotional response can be alcohol consumption or violent behavior while women seek support and understanding for themselves and their family. In the case of the elderly, they are vulnerable due to chronic diseases, nutritional deficits and the lack of family and social support. Finally, boys and girls, not having a complete understanding of the situation, present a limitation when expressing their feelings. According to Ribot et al. (2020), the situation created by an epidemic affects all aspects of childhood development (physical, mental and social). The emotional response of men can be alcohol consumption or violent behavior while women seek support and understanding for themselves and their family. In the case of the elderly, they are vulnerable due to chronic diseases, nutritional deficits and the lack of family and social support. Finally, boys and girls, not having a complete understanding of the situation, present a limitation when expressing their feelings. According to Ribot et al. (2020), the situation created by an epidemic affects all aspects of childhood development (physical, mental and social). The emotional response of men can be alcohol consumption or violent behavior while women seek support and understanding for themselves and their family. In the case of the elderly, they are vulnerable due to chronic diseases, nutritional deficits and the lack of family and social support. Finally, boys and girls, not having a complete understanding of the situation, present a limitation when expressing their feelings. According to Ribot et al. (2020), the situation created by an epidemic affects all aspects of childhood development (physical, mental and social). Boys and girls, not having a complete understanding of the situation, present a limitation when expressing their feelings. According to Ribot et al. (2020), the situation created by an epidemic affects all aspects of childhood development (physical, mental and social). Boys and girls, not having a complete understanding of the situation, present a limitation when expressing their feelings. According to Ribot et al. (2020), the situation created by an epidemic affects all aspects of childhood development (physical, mental and social).

According to the United Nations Committee on the Rights of the Child (2020), children and adolescents (NNA) are one of the most vulnerable populations in the pandemic, as they are exposed to 
serious physical, emotional and psychological consequences due to the restrictions that they mean the closure of schools; loss of contact with peer groups; limitations for movement and recreational activities. Around 860 million children and adolescents will be affected as a result of the quarantine measures (Orgilés et al., 2020).

It is possible to identify four critical areas in childhood that will be affected by the pandemic: education, protection of rights, poverty and mental health:

In the first place, referring to education, this situation has generated an interruption in the learning processes, thus evidencing the gaps and inequalities in access to digital platforms, availability of learning materials in many educational centers and a set of Adverse conditions for developing educational processes within homes, which means for many children a limited or no education.

Situations that violate or threaten children's rights is also another area that presents significant challenges in the context of a pandemic. Family stress occurs due to job loss, isolation, excessive confinement, with subsequent anxiety about health and finances, increasing the risk of violence within the family, which will have a negative impact on childhood, since the home should be the first line of defense and protection of the child, and the stressors related to Covid-19 are threatening that defense (HRW, 2020).

The increase in child poverty would be the third factor of concern that shows the vulnerability of children. As low-income communities are more likely to be exposed to the virus, have higher mortality rates, suffer economically, and receive lower-quality healthcare, the economic downturn will have a number of negative long-term ramifications and impact In the kids. As a result, the pandemic and economic crisis will put children in poverty at even greater risk, greatly exacerbating existing inequalities.

Finally, in relation to the mental health of children, responses such as fear, anxiety, irritability, anguish and anger will inevitably occur, with serious negative health effects due to disruptive events such as the pandemic and the subsequent state of confinement. One of the implications in the individual and collective experiences of populations is the external imposition that restricts freedom of action and movement. This is associated with depressive and post-traumatic stress symptoms; it is lived with displeasure, since it implies the separation of family and loved ones, loss of freedom, uncertainty about the situation of the disease and boredom (Brooks et al., 2020)

In summary, not only are the effects of the pandemic on the physical health of children but it extends much further, in addition to occurring in a scenario where the situation of children in our country was already in a state of crisis, considering the absence of a Law for the Guarantees of Children's Rights, the lack of constitutional recognition and the alarming rates of violence and abuse reported by children themselves (Unicef, 2015).

On the other hand, an investigation developed by Orgilés et al. (2020) conducted a survey of 1,143 parents and caregivers of Italian and Spanish children between 3 and 18 years old. This survey, once completed, provided information on how the quarantine affects their children and themselves, making a 
comparison with their pre-quarantine situation. As main conclusions it can be highlighted that $85.7 \%$ of parents found changes in their children's behavior and emotional state. The most common effect was concentration difficulty, reported by $76.6 \%$ of the parents. Boredom, irritability, restlessness, nervousness, feelings of loneliness, restlessness, and increased worry were reported by more than $30 \%$ of parents. It is also concluded that there would be a relationship between the observed changes and the emotional situation of the parents, since the emotional and behavioral symptoms of the children seem to be positively linked to the well-being of the parents. Thus, based on these findings, it can be said that both children and parents are affected by such a stressful situation as quarantine.

Furthermore, it is important to say that, based on the antecedents presented, quarantines and confinements are events that can produce a radical cut in the experiences of continuity and proximity in childhood in the field of social relations. In this context, the discontinuity and loss of primary bonds gives way to important findings about the relevance and what their affective relationships mean for a child, and how the breaking of these bonds has negative effects on their life experience.

In conclusion, it can be affirmed that everything indicated up to this point is of great importance, since it positions children in a role exclusively of a state of vulnerability. However, in a state of emergency such as the pandemic, it threatens to exclude them from actively participating in civic and political life at a time of profound social and lifestyle changes. Therefore, this is considered an issue that can profoundly affect the human experience and have consequences for the mental health of all individuals.

According to Andrés Tallarda (2020), the coronavirus has caused many changes in societies and one of the main consequences it has left is psychological stress due to the anguish caused by fear of the virus, isolation and economic problems.

In fact, a recent survey conducted by the organization called "Mental Health Research Canada" indicates that mental health has been severely affected and rates of anxiety and depression have risen considerably.

As for the groups that have been most affected emotionally by the impact of the virus, according to Andrés Tallarda (2020), these have been the professionals who work exposed to the virus, such as doctors and nurses. Those people who have contracted fear, or who have not been able to say goodbye to their deceased relatives due to Covid-19, have also been very emotionally affected.

However, people who have gone through serious economic difficulties in their businesses are a group quite psychologically affected by covid-19, even indirectly, since this situation has led to situations of social inequalities and poverty.

According to Marín (2020), all this controversial situation has caused many people to refuse to go outside when possible, due to the development of a fear known as "cabin syndrome". This phenomenon is called restlessness and fear of going outside when our brain has become accustomed to being in the same environment for so long, therefore, fear of changing surroundings occurs. 
This syndrome also implies the fear of contacting other people from abroad, carrying out certain activities such as shopping, or getting on public transport.

The people most at risk of suffering from this syndrome are those who have gone through confinement alone since not having any physical contact with people ends up producing a rejection of having contact with others again.

To overcome this, according to Andrés Tallarda (2020) it is recommended to start going out gradually, as well as to follow all the security measures protocols to avoid contagion since this would cause worse psychological problems. Therefore, it is important to follow the guidelines of social distancing, use of a mask and hydroalcoholic gel so that people have a greater sense of security and thus avoid the appearance of anxiety and anguish.

Psychology has become an important factor in the crisis caused by COVID-19, due to the need for adaptation that each person has had to make to this new situation in which the habits and routines of the entire life have been changed. population, which especially affects children and adolescents.

In this way, the pandemic not only affects physically, but also psychologically. Presenting risks of psychosocial stress and psychological problems, because we find children who have suffered from the disease or have a direct relative, which makes the situation affect them more. In addition, the limitation of access to certain services that they could have, such as psychologists, counselors or teachers, should be added. To all this, we must add the problem of the population with special educational needs, since their needs have not been met as they should and they have lost the routine or habits that helped them to adapt. We also find those students who present stressful situations at home due to negligent parenting practices (alcohol consumption, domestic violence, emotional abuse, etc.), worsening during confinement. In addition, the lack of resources and materials of the students has been noted, preventing them from being able to follow the classes online. In turn, in cases of children who do not have a social disadvantage, it can be observed how it affects their health in the same way, since the use of technological devices increases and as a consequence, sedentary lifestyle, irregular diets or lack of dream. (Brazendale et al., 2017). irregular diets or lack of sleep. (Brazendale et al., 2017). irregular diets or lack of sleep. (Brazendale et al., 2017).

However, the impact of the pandemic and lockdown depends on the age of the children. In children under 2 years of age, they miss their usual caregivers, becoming concerned and upset about the new situation. Children in school years or older may be concerned about the situation, their own safety and that of their caregivers, as well as the concern of their parents showing challenging behaviors, irritability, nightmares, headaches, tummy aches, excessive attachment, loss of interest and attention. While from 13 to 18 , you can find physical symptoms, sleep or appetite problems, isolation from peers and loved ones, but also an increase or decrease in your energy, apathy and inattention to health promoting behaviors . (de la Torre and Pardo, 2018).

All this should be evaluated in order to know the problem, the associated factors that originate it and 
the interventions that should be carried out to overcome it, in a rigorous scientific way.

Confinement from COVID-19 and associated stress can affect children's well-being. For this reason, a study has been carried out with a sample in which 113 adults with children between 3 and 12 years of age participated. Parents responded to a questionnaire about their children's routines during quarantine, their emotional well-being, sleep problems, and their behavior. 69.6\% of parents reported that, during confinement, their children presented negative emotional reactions, these were: leaving tasks unfinished (28.6\%), showing irritability (28.6\%), difficulty concentrating (24.1\%), showing disinterest ( $24 \%$ ) and being discouraged (23.2\%). Orgilés et al. (2020), 31.3\% sleep problems and $24.1 \%$ conduct problems. Children who invested less time in physical exercise (39.3\% did not exercise any day),

After decreeing the state of alarm, teaching activities were suspended, many schools were without resources to offer alternative and quality training to school children. This, together with the prohibition of going outside to play or establish relationships with their peers, could have a negative impact on the emotional well-being of minors. The consequences of confinement could be both psychological and physical. In addition, many mental health professionals have not been able to continue with their interventions, which can aggravate some symptoms in adults, such as depression or drug use, which end up having a negative impact on the child (Espada, Orgilés, Piqueras, \& Morales , 2020. Xie et al. (2020).

In the case of hospitalized children, it has been shown that not attending the classroom is related to higher levels of anxiety (Manueles-Jiménez, Ortiz-González, Serradas-Fonseca, \& Estalayo, 2002).

Confinement conditions are another factor that has been able to influence the well-being of Spanish children.

\section{CONCLUSIONS.}

The confinement situation has been a negative psychological aspect, which has affected families and more specifically children, since it has meant a great change in their lives. As a main aspect, social deprivation must be considered, since the infantile and primary stages are considered one of the most redundant for this aspect to develop, which is constantly evident in ordinary life. This situation produces discomfort, insomnia, eating disorders, irritability, inattention or disinterest. This is coupled with the lack of education, with parents acting as teachers on various occasions due to lack of access to the media, especially in those students who require individualized attention such as a case of a child diagnosed with Autism Spectrum Disorder or an Attention Deficit Hyperactivity Disorder, in which the explanation cannot be given through a video call and focus their attention so that they can carry out the work autonomously. At the same time, they have also not had access to counselors, psychologists, physiotherapists, doctors, etc., who cared for the population through technological means, which has had an impact on mental health. In addition, many children or their relatives have had the disease, which creates fear, insecurity, discomfort and concern about their condition. in which the explanation cannot be given through a video call and focus their attention 
so that they can carry out the work independently. At the same time, they have also not had access to counselors, psychologists, physiotherapists, doctors, etc., who cared for the population through technological means, which has had an impact on mental health. In addition, many children or their relatives have had the disease, which creates fear, insecurity, discomfort and concern about their condition. in which the explanation cannot be given through a video call and focus their attention so that they can carry out the work independently. At the same time, they have also not had access to counselors, psychologists, physiotherapists, doctors, etc., who cared for the population through technological means, which has had an impact on mental health. In addition, many children or their relatives have had the disease, which creates fear, insecurity, discomfort and concern about their condition.

For this reason, it is considered that the creation of a routine habit that includes less time spent using screens, doing physical exercise and socializing with people living together can help alleviate the symptoms of discomfort caused by this confinement . 


\section{REFERENCES}

Brazendale, K., Beets, M. W., Weaver, R. G., Pate, R. R., Turner-McGrievy, G. M., Kaczynski, A. T., Chandler, J. L., Bohner, A. y von Hippel, P. T. (2017). Understanding differences between summer vs. school obesogenic behaviors of children: The structured days hypothesis. International Journal of Behavioral Nutrition and Physical Activity, 14(1). https://doi.org/s12966-017-0555-2

Castillo, M., Castillo, M., Ferrer, M. y González, S. (2020). Depresión infanto-juvenil y otros aspectos de salud mental durante el confinamiento y la pandemia por Sars-Cov-2/COVID-19: Encuesta en contexto escolar. Anales de Pediatria. En https://www.ncbi.nlm.nih.gov/pmc/articles/PMC7532745/pdf/main.pdf

De la Torre, M. y Pardo, R. (2018). Guía para la intervención telepsicología. Colegio Oficial de Psicólogos de Madrid.

Erades, N. y Morales, A. (2020). Impacto psicológico del confinamiento por la COVID-19 en niños españoles: un estudio transversal. Revista de Psicología Clínica con Niños y Adolescentes, 7 (3), pp 27-34. En https://www.revistapcna.com/sites/default/files/006_0.pdf

Espada, J. P., Orgilés, M., Piqueras J. A., y Morales A. (2020). Las buenas prácticas en la atención psicológica infanto-juvenil ante el COVID-19. Clínica y Salud,

31(2), 109-113. https://doi.org/10.5093/clysa2020a14

Manueles-Jiménez, J., Ortiz-González, M., Serradas-Fonseca, M., y Estalayo, L. (2002). Necesidad de asistencia educativa al niño hospitalizado. Enseñanza y Teaching: Revista Interuniversitaria de Didáctica, 20, 243-258.

Ribot, V.C., Chang, N. y González, A.L. (2020). Efectos de la COVID-19 en la salud mental de la población. Revista Habanera de Ciencias Médicas, 19. En http://scielo.sld.cu/pdf/rhcm/v19s1/1729-519X-rhcm-19-s1e3307.pdf

Villegas, M. (2020). Pandemia de COVID-19: pelea o huye: COVID-19 pandemic: fight or flight. Revista Experiencia en Medicina, 6 (1), 3-4. En http://rem.hrlamb.gob.pe/index.php/REM/article/view/424/250

Morales Retamal, C. (2020). Salud mental de los niños, niñas y adolescentes en situación de confinamiento.Anales de la Universidad de Chile, (17), pp. 303-318. doi:10.5354/0717-8883.2020.58931

Comité de los Derechos del Niño (2020). Declaración sobre el grave efecto físico, emocional y psicológico de la pandemia Covid-19 en los niños. https://tbinternet.ohchr.org/Treaties/CRC/Shared\%20Documents/1_Global/INT_CRC_STA_9095_S.pdf Orgilés, M., Morales, A., Delveccio, E., Mazzeschi, C., Espada, J.P. (2020). Immediate psychological effects of the Covid-19 quarantine in youth from Italy and Spain. https://doi.org/10.31234/osf.io/5bpfz

Brooks, S. K., Webster, R. K., Smith, L. E. et al. (2020). The psychological impact of quarantine and how to reduce it: Rapid review of the evidence. Lancet. 2020;395(10227):912-920. https://doi.org/10.1016/S0140-6736(20)30460-8

Unicef (2015). $4^{o}$ Estudio de maltrato infantil en Chile. En https://www.unicef.org/chile/media/1306/file/4to_estudio_de:maltrato_infantil_en_chile.pdf 